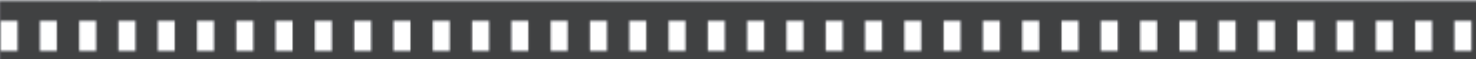

\section{Olhares cruzados sobre Santarém (PA)}

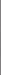

Lila Rosa de Sousa Bemerguy 


\title{
Olhares cruzados sobre Santarém (PA)
}

Crossed views about Santarém (Pará State)

\author{
Lila Rosa de Sousa Bemerguy *
}

Resumo: O presente artigo relata o projeto "Olhares Cruzados" desenvolvido em 2010 pela pesquisadora, no qual resgata a obra de seu avô, ofotógrafo Vidal Bemerguy, que atuou na cidade de Santarém (PA) nas décadas de 1950 a 1970. É apresentado um breve histórico sobre a atividade no estado e são abordadas as questões da temporalidade na fotografia e sua relação com a memória. A autora do projeto revisita e fotografa os espaços retratados por seu avô, apontando nessas imagens mudanças da cena urbana em distintos momentos, com um lapso temporal de aproximadamente 50 anos.

Palavras-chave: Fotografia paraense. Santarém (PA). Vidal Bemerguy. Fotografia e memória.

Abstract: This article reports the project "Olhares Cruzados"
("Looks Crusaders") developed in 2010 by the researcher, which
rescues the work of her grandfather, the photographer Bemerguy
Vidal, who served in the city of Santarém (PA) in the decades from
1950 to 1970 . The paper gives a brief history of activity in the state
and addresses the issues of temporality in photography and its relation
to memory. The author revisits the project and photograph the spaces
depicted by her grandfather, pointing changes in these images of the
urban scene at different times, with a delay of approximately 50 years.

Keywords: Paraense photography. Santarem (PA). Vidal Bemerguy. Photography and memory.

* Graduada em Comunicação Social - Habilitação Jornalismo pela Universidade Federal do Pará (UFPA). Especialista em Comunicação e Política nos Órgãos Públicos pela Universidade da Amazônia (Unama). Comunicadora social, jornalista e fotógrafa. Docente das disciplinas Introdução à Fotografia e Fotojornalismo I e II no Instituto Esperança de Ensino Superior (IESPES). E-mail: lilabemerguy@gmail.com 


\section{Introdução}

O projeto "Olhares Cruzados" foi proposto pela jornalista e fotógrafa Lila Bemerguy ao Instituto de Artes do Pará (IAP), em 2010, pelo qual recebeu a Bolsa de Pesquisa e Criação Artística concedida pela instituição a artistas paraenses. A pesquisa buscou resgatar e identificar o trabalho do fotógrafo Vidal Macedo Bemerguy, seu avô paterno, falecido em 1978 na cidade de Santarém, localizada no oeste do estado do Pará.

O objetivo foi o de apresentar um olhar do passado e um olhar contemporâneo sobre a cidade de Santarém e, para isso, a pesquisadora percorreu e registrou, em 2010, as mesmas paisagens retratadas pelo avô entre 1950 e 1970 . A memória diretamente relacionada ao ato fotográfico, o resgate e divulgação da obra de um fotógrafo desconhecido, bem como a revisitação e os novos registros dos locais por ele retratados, foram os fundamentos do projeto.

A paisagem de uma cidade percebida por dois olhares, em dois momentos, com intervalo de 50 anos, elucidou a noção de temporalidade ligada às imagens e os registros da cena urbana, modificada pelo tempo, traduzem uma nova realidade de mudança e crescimento de locais habitados pelo homem.

No projeto, dois olhares se cruzam e mostram locais que foram não somente modificados, mas não mais existem ou foram totalmente descaracterizados. Permanecem apenas nas imagens amareladas pelo tempo, que possuem fascínio e beleza próprios. "E mais seduzem as fotos quanto mais envelhecem. Elas podem até não ser formalmente belas, mas, da ausência imbuída na presença, que nelas notamos, deriva um apelo do vago, do inacessível e do não mais existente.” (NUNES, 1998, p.33).

O resultado final de "Olhares Cruzados" foi apresentado em instalação fotográfica na cidade de Santarém. A mostra trouxe as imagens coletadas na pesquisa, de Vidal Bemerguy e outros fotógrafos "anônimos", e as produzidas em 2010, nos mesmos lugares registrados há cerca de 50 anos. 


\section{Fotografia: um relato do tempo}

A fotografia estabelece relação íntima com a temporalidade, seja por sua natureza de trazer um recorte de determinado espaço/tempo, seja por sua própria condição de funcionar como um recurso da memória, que tem o poder de reativar lembranças, recordações e imagens de momentos, pessoas e lugares que não existem mais. Calvino (1992), em um trecho do conto Aventura de um fotógrafo, resume o modo de como a humanidade apreendeu a aventura de poder congelar o tempo:

Com a chegada da primavera, os habitantes das cidades, às centenas de milhares, saem aos domingos levando o estojo a tiracolo. E se fotografam. Voltam satisfeitos como caçadores com o embornal repleto, passam os dias esperando com doce ansiedade para ver as fotos reveladas (ansiedade a que alguns acrescentam o prazer sutil das manipulações alquímicas na câmara escura, vedada às intrusões dos familiares, exalando um cheiro acre dos ácidos), e somente quando põem os olhos nas fotos parecem tomar posse tangível do dia passado, somente então aquele riacho alpino, aquele jeito do menino com o baldinho, aquele reflexo do sol nas pernas da mulher adquirem a irrevogabilidade daquilo que já ocorreu e não pode mais ser posto em dúvida. O resto pode se afogar na sombra incerta da lembrança. (CALVINO, 1992, p.53).

As fotografias têm vestígios, pistas de acontecimentos que foram ou não experimentados pelo observador, indicando como foi ou teria sido determinado evento. "Também nas imagens fotográficas encontramos indícios, sejam eles voluntários ou involuntários, materializados mediante um sistema de representação visual que se tornou factível nas primeiras décadas do século XIX.” (KOSSOY, 2007, p.39). Elas trazem marcas do passado, e podem registrar desde os anéis de Saturno, ao "movimento de uma rua na segunda década do século XX, a arquitetura dos edifícios, as fachadas dos estabelecimentos comerciais e de serviços, o vestuário dos transeuntes". (KOSSOY, 2007, p.41). 
A possibilidade de trazer ao espectador paisagens do passado fortalece a ligação da fotografia com a memória, como um suporte para que não esqueçamos o que ali está registrado, como um testemunho. (SONTAG, 2004). Nunes (1998, p.24) fala da força com que a fotografia reaviva a memória, mesmo sem a materialidade do objeto de registro: "Um real que não se pode mais tocar, mas que nos toca: cada imagem fotográfica abre a rede expansiva do nosso imaginário, arrasta-nos com sua força de sugestão e nos comove." Tal força pode muitas vezes sobressair à questão estética da fotografia, transferindo sua importância como obra de arte para sua condição como objeto de resgate da memória.

Nunes (1998) aborda em um de seus textos o paradoxo da fotografia, o qual chama de "fulguração do instante", ou seja, a condição de ter captado algo que já faz parte do passado, mas que fica "detido" pela imagem fixada. Se fosse eleito um lema para a técnica fotográfica, seria em sua opinião, o dito no trecho do Segundo Fausto de Goethe: "Detém-te, és tão belo". Porém, "o instante só se detém ao passar" (NUNES, 1998, p.32), afirma o autor, em uma reflexão sobre o tempo, que embora não possa ser paralisado, fica congelado ao ser fixado em suporte fotográfico. E segue sua abordagem, diferenciando o tempo que cerca a imagem do tempo a que somos submetidos:

\footnotetext{
Por isso, o que se fotografa hoje já se torna um ontem, o que já foi e não é mais presente. Nenhum agora se fixa sem converter-se em outrora. Esse excesso do passado - e dum passado que lateja defronte ou perto de nós - sobre presente e futuro, dos quais se distancia, é o tempo da imagem subvertendo o nosso tempo psicológico, que corre do presente ao passado, na expectativa do futuro. (NUNES, 1998, p.32).
}

Em sua concepção, o projeto "Olhares Cruzados" buscou resgatar imagens de Santarém, do fotógrafo Vidal Bemerguy, e revisitar os mesmos lugares, fotografando-os novamente, apontando para a ação do tempo e do homem sobre a paisagem. 
Kossoy (2007, p.143) fala de um "tempo reciclado", que acontece quando determinadas imagens "voltam" de alguma maneira, sob nova forma, ou com nova função. Na conclusão da pesquisa, percebemos haver feito essa "reciclagem" de alguns aspectos da paisagem urbana de Santarém, lançando sobre esses lugares um novo olhar.

\section{A fotografia no Pará e em Santarém}

Ao passearmos pela história da fotografia no Pará, não seria exagero afirmar que o ofício de fotógrafo se desenvolveu, e ainda se faz presente, de maneira fecunda e intensa nesse território repleto de imagens que despertam a curiosidade do olhar estrangeiro.

De acordo com Fernandes Junior (2002), o primeiro fotógrafo que chegou ao Pará foi o norte-americano Charles DeForest Fredricks, em 1844. Ele se estabeleceu comercialmente na capital, Belém, em 1846, e ali trabalhou por três meses. Depois foi para outros estados, passando pelo Maranhão e Pernambuco, conforme constatou Kossoy (2002) em seu dicionário de fotógrafos. De sua passagem por Belém pouco ficou registrado, porém, Fernandes Junior (2002, p.20) ressalta que o local é considerado "como uma das primeiras cidades brasileiras a possuir um profissional de daguerreotipia, no início dos anos quarenta do século XIX".

Após Fredricks, outros fotógrafos passaram pelo Pará, destacandose o alemão Albert Frisch, em 1865, que produziu uma série de imagens veiculadas pela Casa Leuzinger, do fotógrafo George Leuzinger, com sede no Rio de Janeiro. "Pela originalidade desse trabalho, considera-se que seja um dos primeiros ensaios na área de etnografia visual." (FERNANDES JUNIOR, 2002, p.21). No período de 1860 a 1869, Kossoy (2002) registra Guillherne Potter, Antônio Maria de Mattos, Campbell, José Carlos Gonçalves, Antônio Lima, Veyret e Felipe Augusto Fidanza como profissionais que atuaram no Pará. Este último se tornou um dos mais importantes nomes da fotografia no estado. 
Em 1867, o Imperador Dom Pedro II, um amante da fotografia, veio a Belém para o ato de abertura dos portos da Amazônia ao comércio exterior. (NUNES, 1998). Para registrar a solenidade, trouxe consigo o fotógrafo italiano Felipe Augusto Fidanza, que acabou permanecendo em Belém. Fidanza possuía um ateliê na rua Santo Antônio, no centro da cidade, e documentou o cotidiano local. Parte de sua obra ficou registrada no Álbum do Pará, nas edições de 1899 a 1902. O estúdio de Fidanza foi mantido por outros profissionais até 1969 e "essa longevidade é uma das maiores de que temos conhecimento no Brasil". (FERNANDES JUNIOR, 2002, p.22).

O pesquisador aponta que no período entre 1846 e 1920, vários profissionais registraram Belém e região. Além disso, os álbuns produzidos nos governos de José Paes de Carvalho, Antônio José de Lemos e Augusto Montenegro são algumas das fontes da produção iconográfica no estado nos quais é possível perceber "não só o desenvolvimento do estado, mas também a qualidade da produção fotográfica paraense". (FERNANDES JUNIOR, 2002, p.22). O material trazia imagens da capital e de cidades do interior: "panorâmicas de cidades como Alenquer e Santarém concorrendo com as de Belém". (NUNES, 1998, p.31).

Em 1955 foi fundado em Belém o Foto Clube Pará, a partir de encontros de fotógrafos na casa comercial Fotografia Amazônia, de Fritz Liedman. "Desses encontros participaram Amílcar Leão, Gratuliano Bibas, Moacir Moares, Eliezer Freire, Anselm Pitman, Francisco Bacelar, Raimundo Moura e outros." (FERNANDES JUNIOR, 2002, p.22). Em 1965 e 1966 foram realizados pelos fotoclubistas, respectivamente, o I e o II Salão Paraense de Arte Fotográfica, de âmbito nacional.

Após os salões, o movimento fotoclubista perdeu força e, segundo Fernandes Júnior (2002, p.23), “a partir dos anos 70, a fotografia paraense inicia uma mudança paradigmática". Segundo o autor, um dos responsáveis por essa mudança foi o fotógrafo Luiz Braga, que traçou uma brilhante trajetória a partir de 1974 e atualmente mantém seu estúdio em Belém. Outros profissionais, oriundos do fotojornalismo, como Porfírio da Rocha e Pedro Pinto, também foram importantes nesse processo. 
Para Nunes (1998), a geração anterior é vinculada ao Foto Clube Pará, assim como a atual é ligada ao fotógrafo Miguel Takao Chikaoka, em razão de sua atuação a frente de uma escola, a Fotoativa, por ele criada e mantida desde 1984. (NUNES, 1998, p.30). O paulista Chikaoka chegou a Belém em 1980, dando início à escola que influenciou - e ainda influencia - grande número dos fotógrafos paraenses que começaram a atuar nessa época e traçaram carreiras independentes, nos mais diversos estilos.

Os relatos acima tratam de fatos relacionados a fotógrafos estabelecidos na capital, Belém. Alguns deles passaram por Santarém, cidade localizada no oeste do Pará, fundada em 1661, ano de chegada de missão de padres jesuítas no local de morada indígena que denominaram “aldeia dos Tapajós". (FONSECA, 2006). Segundo o autor, em 1758 o lugar recebeu o nome de Santarém em homenagem à cidade de mesmo nome em Portugal, e a colonização portuguesa pode ser percebida nos antigos casarões que restaram no centro da cidade, conhecida por seus habitantes como "Pérola do Tapajós".

De acordo com uma pesquisa, ainda em desenvolvimento, coordenada pela doutora em antropologia Ligia Simoniam, do Núcleo de Altos Estudos Amazônicos da Universidade Federal do Pará (NAEA/ UFPA), o primeiro fotógrafo santareno foi Apollonio Alves Pereira Fona, que nasceu em 1897 e faleceu na cidade em 1938. "Em seu decorrer, acessou-se mais de uma centena de fotos provenientes de arquivos particulares e de um institucional." (SIMONIAN, 2007, p.24). Além disso, na obra de Apollonio foram encontrados "feitos então inexistentes em Belém, como as fotografias construtivistas”. (SIMONIAN, 2007, p.24).

Os relatos obtidos por meio de entrevistas com pessoas próximas a Vidal Bemerguy indicam que ele foi o terceiro fotógrafo a fixar moradia em Santarém, em 1950. Antes dele, além de Apollonio Fona, morou na cidade o alemão Bernard Keuffer, que depois se transferiu para Belém. Em 1966, chegou à cidade o peruano Alfonso Gimenez, que permaneceu até a sua morte, em 2011. Atualmente, Santarém é a segunda maior cidade do estado e contabiliza diversos profissionais fotógrafos em atividade. 


\section{A pesquisa: o projeto}

O projeto "Olhares Cruzados"1 foi desenvolvido no ano de $2010 \mathrm{e}$ sua fase inicial deu-se com a pesquisa de informações sobre Vidal Bemerguy, com entrevistas realizadas com familiares e conhecidos. Após a pesquisa oral, iniciou-se a coleta documental de imagens da cidade em álbuns organizados pelo fillho do fotógrafo, Emir Bemerguy, com fotografias legendadas e identificadas de acordo com o ano de produção. O Instituto Boanerges Sena, localizado em Santarém, também cedeu imagens de seu acervo e foram feitas coletas avulsas, com pessoas que possuíam uma ou mais fotografias guardadas em álbuns de família.

Parte das fotografias coletadas é de autoria de Vidal Bemerguy, informação que não está explícita nas imagens, por meio de assinatura, mas confirmada pelas fontes consultadas no projeto. Decidimos divulgar na mostra final e nas publicações posteriores somente as imagens obtidas do acervo pessoal de Emir Bemerguy, que organizou em álbuns as fotografias originais que coletou do pai. A autoria foi identificada por meio de informações obtidas com pessoas ligadas ao fotógrafo, como o seu filho Emir Bemerguy, Ozair Queiroz que trabalhou como aprendiz de Vidal Bemerguy no Foto Santarém e o fotógrafo Alfonso Jimenez (morto em 2011), que o conheceu nos anos 1970.

$\mathrm{Na}$ fase final, foi concluída a produção de imagens na cidade de Santarém, feitas com câmera analógica e filmes P\&B ISO 400. Foram produzidos cerca de 360 fotogramas nos mesmos locais fotografados por Vidal Bemerguy entre 1950 e 1970.

O resultado do trabalho foi montado em instalação fotográfica em um casarão do século XIX (1867), chamado de "Solar Barão de São Nicolau", localizado à rua Floriano Peixoto, região central de Santarém. Apresentar o resultado na cidade foi fundamental para o fechamento do projeto, que também teve o objetivo de dialogar com a memória da

\footnotetext{
${ }^{1}$ Projeto financiado por meio da Bolsa de Pesquisa e Experimentação Artística concedida via edital público de seleção, pelo Instituto de Artes do Pará (IAP), no ano de 2010.
} 
localidade, mostrando uma paisagem do passado aos seus moradores e despertando o olhar dos mesmos sobre seu próprio ambiente. As imagens do passado e do presente de uma cidade, expostas no mesmo espaço, forneceram não apenas a noção de temporalidade, como também da transformação do lugar em espaço no período de aproximadamente 50 anos.

\section{A pesquisa: sobre Vidal Bemerguy}

Nos relatos colhidos para o projeto, verificou-se que Vidal Bemerguy não se via com um artista criador e sim com um técnico da fotografia, o que não altera a importância de seu trabalho, pois ao longo da história da fotografia profissionais como ele, por vezes identificados como "anônimos", representaram grande parte dos que exerceram o ofício de fotógrafo. A febre do retrato em São Paulo, relatada na obra de Grangeiro (2000, p.39), demonstra o impulso tomado pela fotografia entre 1862 e 1886, a partir do momento em que as classes menos abastadas tiveram acesso a esse tipo de fotografia "por séculos restrito a poucos - com significados relacionados à honra e à distinção" tornando-se, em pouco mais de duas décadas, "um objeto amplamente consumido".

Sobre os anônimos, Kossoy (2007, p.66) afirma que representam "a massa dos artesãos da imagem, jamais mencionados por qualquer história”. Ele defende que o estudo sobre esses fotógrafos deve provocar avanços significativos tanto na área da fotografia e na memória histórica e fotográfica do país. O pesquisador afirma que a história da fotografia repete exaustivamente nomes consagrados em diferentes categorias: retratos, documentário social, fotografia artística etc., apontando-a como uma concepção falha, pois deixa de mencionar inúmeros outros fotógrafos que jamais fizeram parte da lista de fotógrafos tradicionais, elitizando a história e reforçando a visão estreita que se tem de determinada região ou de um país. Uma das grandes fontes para resgatar esses nomes do anonimato, segundo ele, são os álbuns de família. 
Vidal Bemerguy era conhecido como fotógrafo somente na cidade de Santarém, e por um pequeno número de pessoas, ligadas à família ou parentes. Os álbuns do filho Emir Bemerguy, que identifica local e ano das imagens, foram fundamentais na coleta de material e um deles traz a anotação "quase todas as fotografias aqui contidas foram tiradas por Vidal Bemerguy".

Os relatos feitos pelos entrevistados na primeira fase do projeto resumem a personalidade do fotógrafo. Ademar $\mathrm{Cunha}^{2}$, cunhado, com 82 anos, relata que Vidal Bemerguy nasceu em Anajás, uma pequena vila no interior do Pará, casou-se com Raimunda Ribatejo Bemerguy e foi com ela viver em Fordlândia, cidade que representava o sonho de Henry Ford, cujo projeto foi iniciado em 1927. Depois se mudou para Belterra, também incluída nos projetos da borracha, já com os filhos Eros, Ércio, Emire Edith.

Em Belterra, onde viveu na década de 40, Vidal Bemerguy trabalhava "para os americanos", conta Cunha ${ }^{3}$. Para tanto, aprendeu a falar inglês, o que lhe possibilitou trabalhar como intérprete. "Não sei como ele aprendeu. Eu era criança, mas não via o Vidal pegando em livros", lembra o cunhado. Foi em Belterra que ele teve seu primeiro contato com o equipamento fotográfico, possivelmente por intermédio de algum forasteiro. Mas ali ele ainda não trabalhou com a fotografia profissionalmente, pois exercia o cargo de chefe do almoxarifado do projeto Ford, e apenas usava o equipamento para fazer fotografias " $3 \times 4$ " e de amigos, reveladas no quarto de sua casa, que havia sido transformado em laboratório.

Com a decadência do projeto em Belterra, Vidal Bemerguy viu-se em apuros para sustentar a família. Por isso resolveu mudar para Santarém, onde permaneceu de 1950 até sua morte, em 1978.

Emir Bemerguy ${ }^{4}$ lembra que o envolvimento de seu pai com fotografia começou quando a Companhia Ford do Brasil saiu do país.

\footnotetext{
${ }^{2}$ CUNHA, Ademar: Belterra, 2010. Entrevista concedida a Lila Bemerguy, em 16 de maio de 2010, na residência do entrevistado.

${ }^{3}$ CUNHA, Ademar: Belterra, 2010. Entrevista concedida a Lila Bemerguy, em 16 de maio de 2010, na residência do entrevistado.

4 BEMERGUY, Emir. Santarém, 2010. Entrevista concedida a Lila Bemerguy, em 22 de maio de 2010, na residência do entrevistado.
} 
"Ele ficou desgostoso. Queria continuar a ser funcionário da Companhia", relata. Em Santarém, o fotógrafo iniciou com um laboratório em casa, na área da frente, e contava com a ajuda dos filhos, que aprenderam com o pai o processo de revelação. Emir lembra que a habilidade com a língua inglesa facilitou o acesso do pai aos livros de fotografia disponíveis na época, e que na cidade já atuava como fotógrafo o alemão Bernard Keuffer, que depois se transferiu para Belém. "Com três meses em Santarém, meu pai já era o principal fotógrafo da cidade."

O Foto Santarém estava localizado no centro da cidade e recebia encomendas de revelações de filmes, ampliação de imagens, 3x4, eventos sociais, dentre outros, com uma grande demanda principalmente de cópias.

Emir Bemerguy relata um episódio que demonstrou a capacidade inventiva de seu pai. Certa vez faltou o químico revelador e o fotógrafo, com encomendas a entregar, não conseguiu adquirir o produto pela dificuldade de acesso do material a localidade. "Ele disse que iria arrumar uma fórmula e um meio de prepará-lo. Passou uns quinze dias quebrando a cabeça até que ele chegou comigo e disse: achei!"’. Ele lembra que um dos componentes usados pelo fotógrafo era a soda cáustica.

Com a obrigatoriedade das fotografias $3 \times 4$ nos documentos, era grande a demanda por serviços. Vidal Bemerguy ganhou um bom dinheiro, suficiente para ajudar na formatura do filho Emir, em Belém. O entrevistado diz que seu pai também fotografava eventos e festas de família, e que por cerca de 20 anos viveu dos honorários desse ramo.

Outra atividade que marcou a vida do fotógrafo foi a "cópia fotostática". O fotóstato era um aparelho usado para tirar fotocópias diretamente em papel de cópia, com a imagem na posição certa, sem uso de negativo. Era uma novidade na época e ele era o único que tinha essa tecnologia na cidade, e fazia o trabalho sozinho, para não revelar a ninguém "seu segredo profissional”. Essa atividade gerou ganhos financeiros, pois o processo era complicado e o serviço custava caro.

Aos poucos, o trabalho foi abandonado, principalmente quando o fotógrafo foi convidado por um prefeito para ser o tesoureiro municipal 
e, aliado a isso, "enjoou" de registrar eventos. Emir Bemerguy ${ }^{5}$ lembra que seu pai não tinha a preocupação de assinar suas imagens, e que seu trabalho como laboratorista tinha muita qualidade. "Eu não lembro de nenhuma fotografia feita por ele que amarelasse."

Como neta de Vidal Bemerguy, lembramos da época de infância, de avô sério, mas terno com os netos. Costumava nos dar papel fotográfico, usado para brincar ao sol. Não sabíamos, mas produzíamos fotogramas, colocando objetos em cima daquele papel, e deixando na luz "para ficar a marca". É emocionante lembrar disso e perceber que essa foi a semente da minha paixão pela fotografia.

\section{A pesquisa: resultados}

Ao observar as fotografias de determinados espaços da cidade de Santarém (PA), retratados há cerca de cinquenta anos, tem-se pistas de como eram os locais no passado, que, mesmo com as transformações sofridas ao longo do tempo, fazem parte do processo comum da urbanização. Algumas dessas mudanças foram naturais diante do crescimento da cidade e das vias urbanas. Outras representaram a mutilação de prédios históricos, sua descaracterização ou total destruição.

Apesar de ser um elemento de fixação da memória, a imagem fotográfica possui elementos que ultrapassam a sua própria superfície. "Naquilo que não tem de explícito, o tema registrado tem sua explicação, seu porque, sua história. Seu mistério se acha circunscrito, no espaço e no tempo, à própria imagem." (KOSSOY, 2007, p.60). Esses elementos implícitos geralmente só são identificados por aqueles que têm conhecimento acerca do tema ou possuem alguma relação com o que ali está retratado. Como moradora da cidade, pude observar nas fotografias

${ }^{5}$ BEMERGUY, Emir. Santarém, 2010. Entrevista concedida a Lila Bemerguy, em 22 de maio de 2010 na residência do entrevistado. 
antigas, locais que frequentava quando criança, alguns modificados, mas que permanecem com os traços do passado. A "Padaria Lucy" (Figura 1) um dos lugares fotografados, era o ponto do pão, do sorvete e do lanche. Atualmente, o prédio está abandonado e em ruínas, restando no local uma balança de ferro, que lembro ter usado algumas vezes, e a placa com os sabores dos sorvetes. O prédio intacto pode ser visto no lado esquerdo da fotografia (Figura 2) feita por Vidal Bemerguy em 1963.

Figura 1 - Interior da Padaria Lucy, desativada

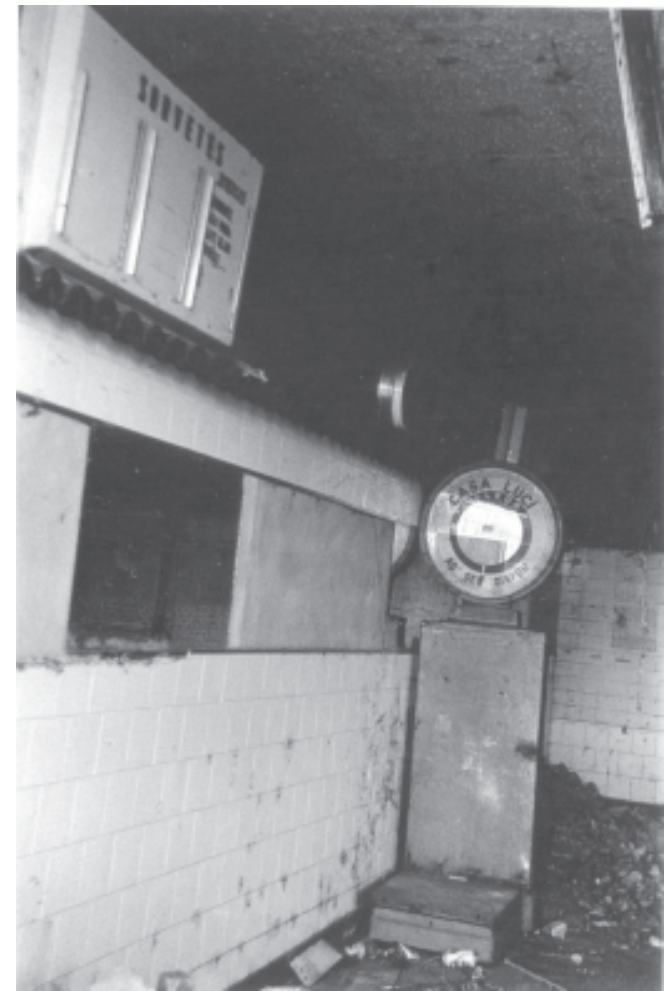

Fotografia: Lila Bemerguy

Fonte: Acervo pessoal de Lila Bemerguy 
Figura 2 - Imagem geral da frente da cidade em 1963.

O primeiro prédio à esquerda é a Padaria Lucy

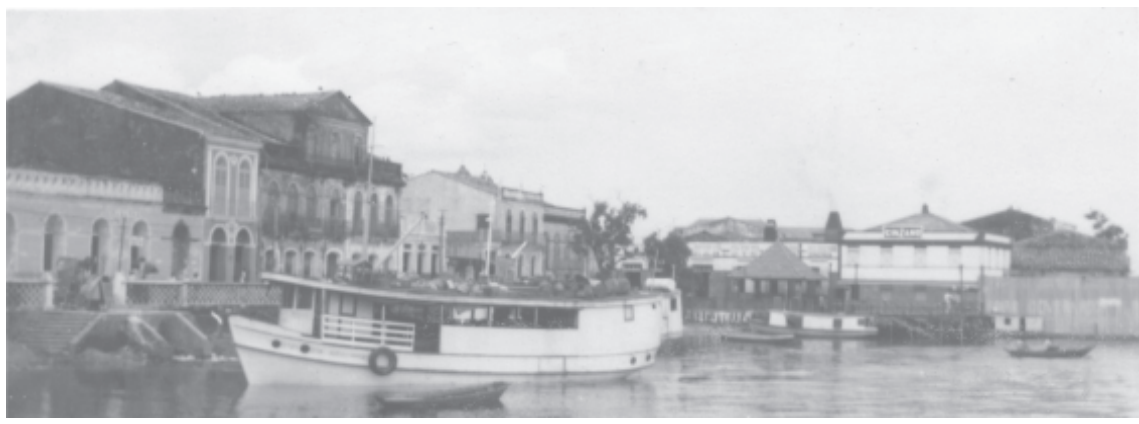

Fotografia: Vidal Bemerguy

Fonte: Acervo pessoal de Emir Bemerguy

Nas ruas do centro, retratadas por Vidal Bemerguy sem veículos, tranquilas, com poucas lojas e muitas residências (Figuras 4 e 6 ), vê-se hoje o movimento dos carros, do comércio (Figuras 3, 5 e 7). O poeta e escritor Emir Bemerguy (2010, p.45) relata em crônica escrita em 1977: “Ontem, Santarém... vidinha quieta... catraias e cuias... ausência de veículos... O clarão do luar, mais intenso que a débil chama das lâmpadas públicas, convidando às líricas serenatas." Sobre o progresso da cidade, lembra um trecho de seu próprio poema, escrito no ano de 1973, dizendo que "entretanto, devagarzinho, como eu disse num poema, o progresso foi chegando. Eu nem sei direito quando, tanta coisa aconteceu!". E continua falando do desenvolvimento urbano: "Movimentam-se as avenidas, as fábricas são erguidas, há lojas em profusão." (BEMERGUY, 2010, p.45).

Ao mesmo em que se curva ao poder do tempo, Emir Bemerguy (2010, p.50) critica as mutilações sofridas e as tentativas de contê-las:

Os sobradões da Rua Lameira Bittencourt, relíquias de uma época, vão sendo retalhados, divididos como sabão a varejo, e nem o venerando 'Castelo' escapou às marretadas deformantes. Um grupo de influentes santarenos, inconformados com tudo isso, vem lutando para conter a avalanche iconoclasta e talvez ainda consiga deter a onda de irracionais mutilações. 
Figura 3 - Rua 15 de Novembro, centro de Santarém, 2010

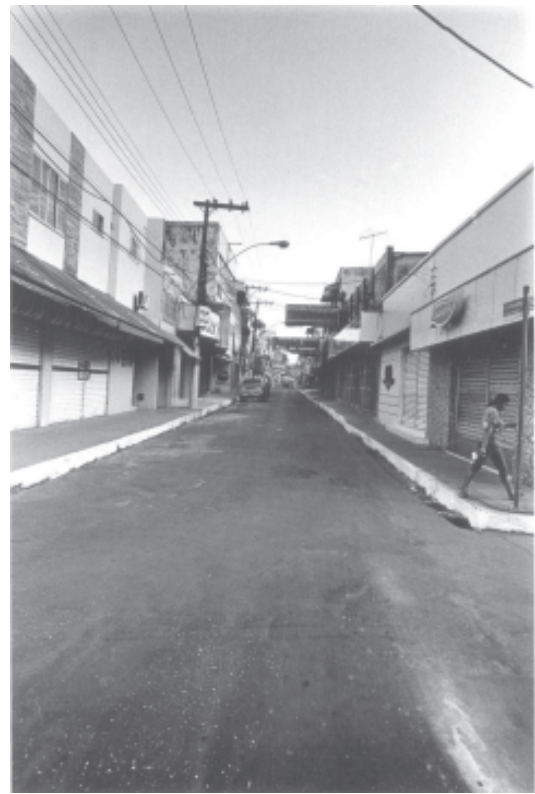

Fotografia: Lila Bemerguy

Fonte: Acervo pessoal de Lila Bemerguy

Figura 4 - Rua 15 de Novembro, no ano de 1950

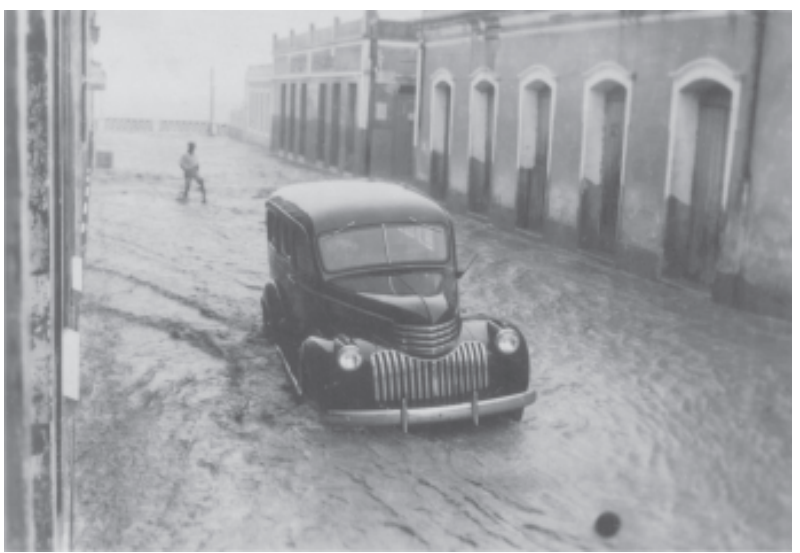

Fotografia: Vidal Bemerguy

Fonte: Acervo pessoal de Emir Bemerguy 
Figura 5 - Rua Lameira Bittencourt, centro de Santarém, em 2010

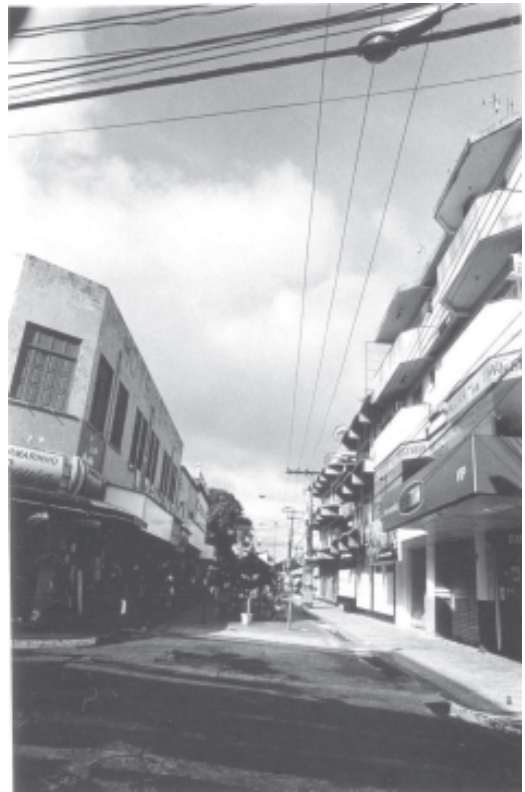

Fotografia: Lila Bemerguy

Fonte: Acervo pessoal de Lila Bemerguy

Figura 6 - Rua Lameira Bittencourt, centro de Santarém, em 1953

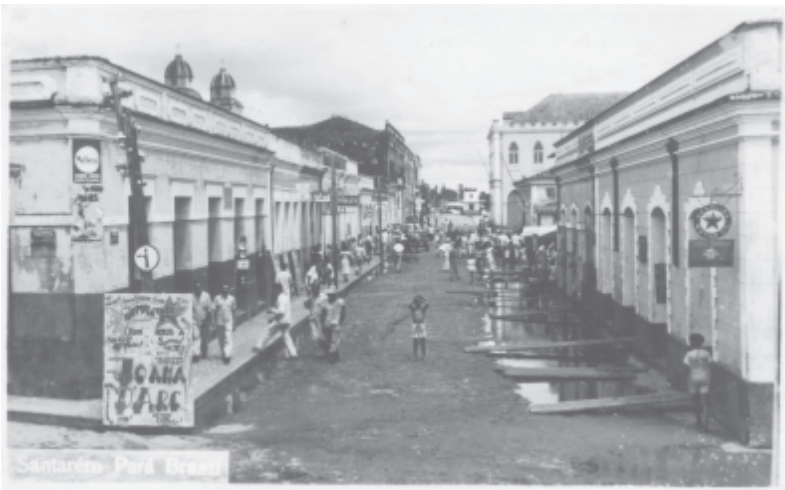

Fotografia: Vidal Bemerguy

Fonte: Acervo pessoal de Emir Bemerguy 
Figura 7 - Rua Siqueira Campos, centro, em 2010

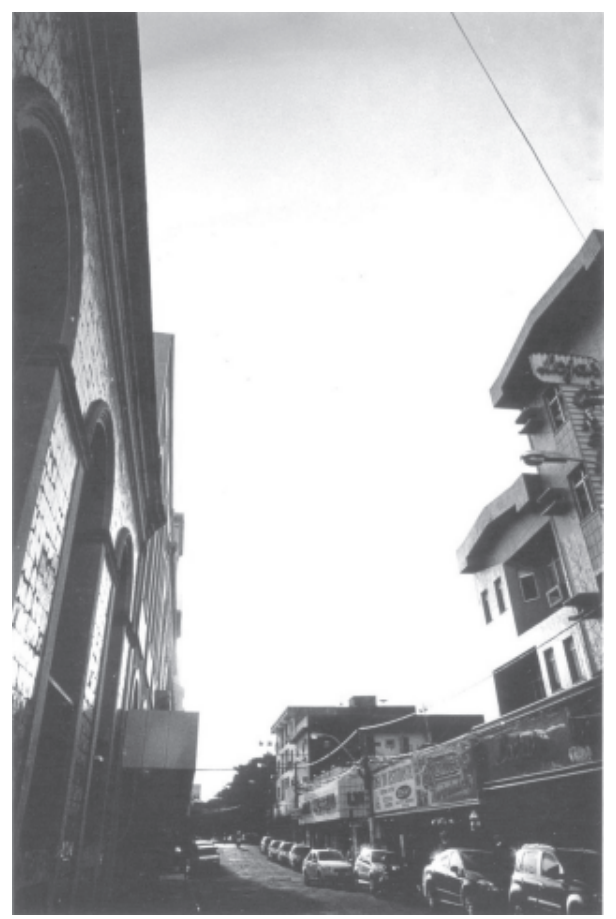

Fotografia: Lila Bemerguy

Fonte: Acervo pessoal de Lila Bemerguy

No decorrer da produção, nos deparamos com as mesmas paisagens vistas por Vidal Bemerguy, modificadas pelo tempo, e outras, que tomaram o lugar daquelas retratadas há 50 anos. Os prédios do Cinema Olímpia (Figuras 8 e 9) e do Centro Recreativo (Figuras 10 e 11) são exemplos de locais que permanecem em pé, porém usados para outros fins ou à espera de destinação. O cinema foi fundado em 1924, demolido e reconstruído em 1947, recuperado após um incêndio em 1971, e desativado em 1986. (FONSECA, 2006). Atualmente, no prédio, funciona um templo pentescostal. O Centro Recreativo, local de festas e reuniões das famílias tradicionais de Santarém, foi fundado em 1934, sendo a nova sede inaugurada em 1943. (FONSECA, 2006). Atualmente, permanece fechado para reforma. 
Figura 8 - Detalhe do Centro Recreativo, 2010

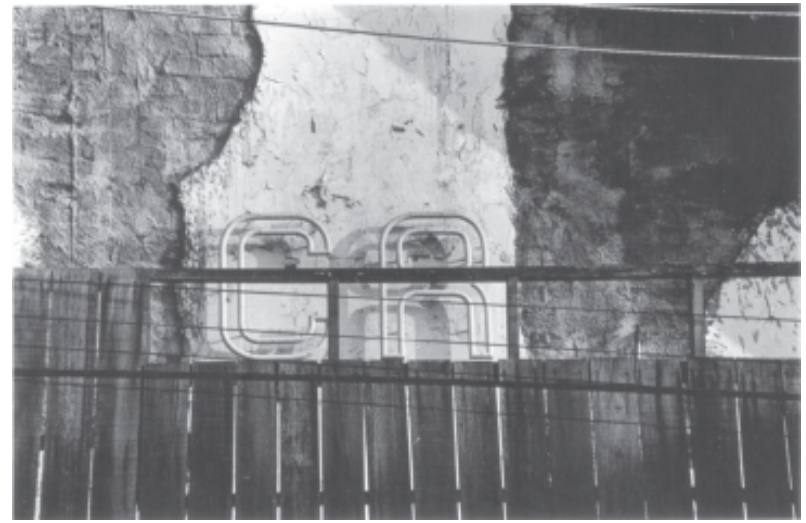

Fotografia: Lila Bemerguy

Fonte: Acervo pessoal de Lila Bemerguy

Figura 9 - Centro Recreativo, em 1950

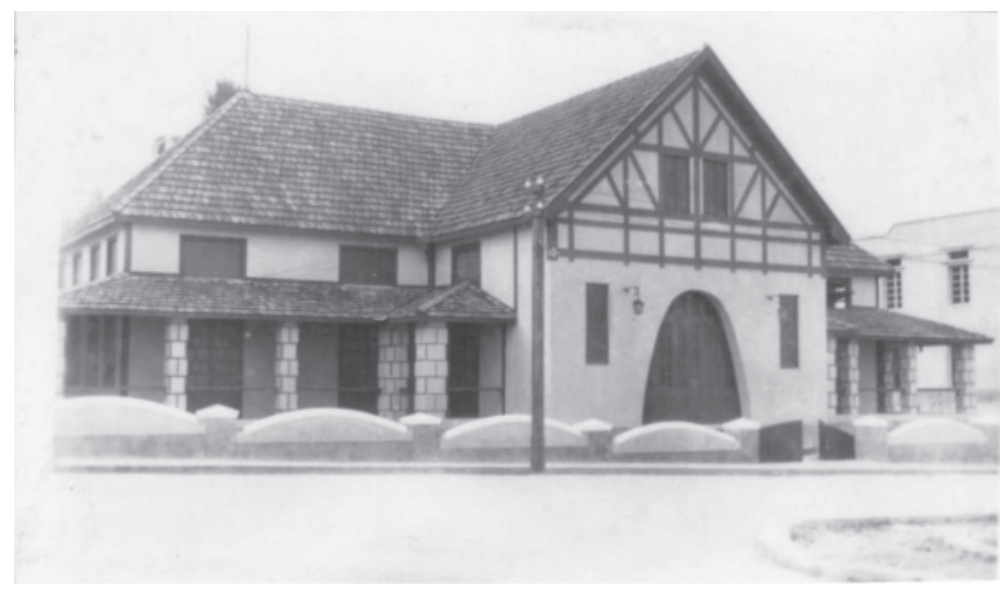

Fotografia: Vidal Bemerguy

Fonte: Acervo pessoal de Emir Bemerguy 
Figura 10 - Detalhe da Praça da Matriz, com o antigo Cine Olympia ao fundo

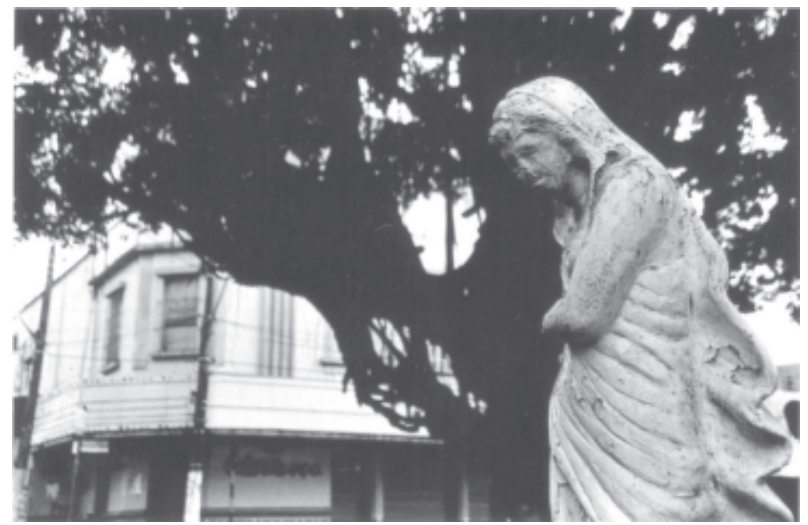

Fotografia: Lila Bemerguy

Fonte: Acervo pessoal de Lila Bemerguy

Figura 11 - Cine Olympia, em 1953

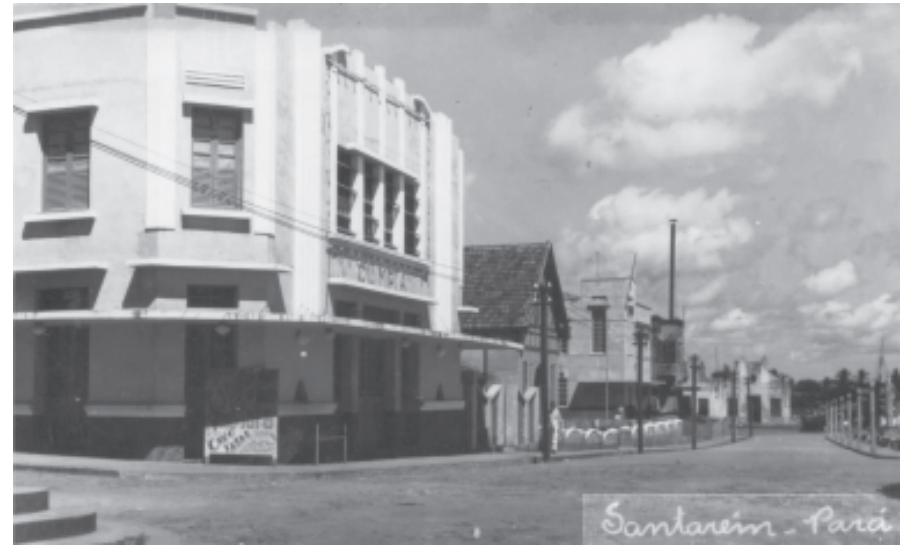

Fotografia: Vidal Bemerguy

Fonte: Acervo pessoal de Emir Bemerguy

Outro local registrado na pesquisa foi o que restou do antigo trapiche da cidade (Figura 12). Vidal Bemerguy também trabalhou como "trapicheiro", conforme informação escrita em legenda no álbum organizado por Emir Bemerguy na fotografia (Figura 13): "Primeiro navio de grande porte que atracou no trapiche de Santarém: Rio Guaporé; a dezenove de 
fevereiro de 1961. O trapicheiro era Vidal Bemerguy." O local, todo feito em madeira de lei, foi por quase um século o ponto de atracação dos barcos que chegavam a Santarém. A primeira versão foi construída em 1884, passou por reformas e foi desativado em 1974, para dar lugar a um novo "cais do porto", de acordo com Fonseca (2006, p.129), "pelos reclamos do progresso que vem a passos de gigante".

Figura 12 - Restos do trapiche

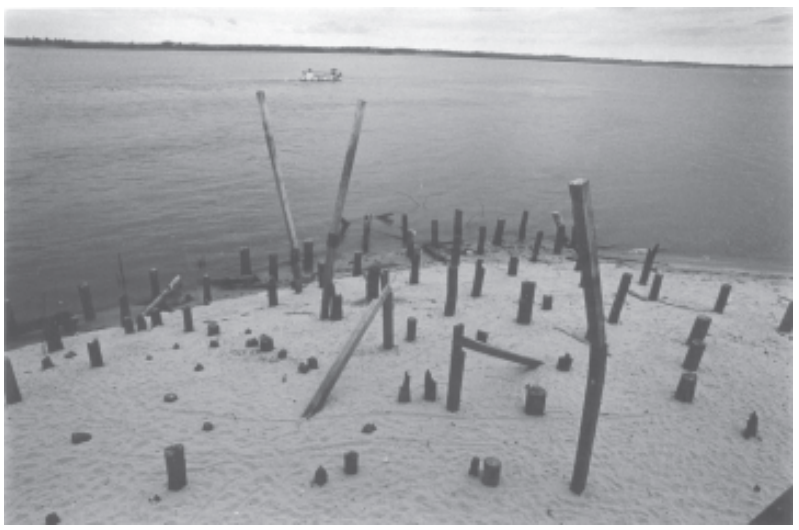

Fotografia: Lila Bemerguy

Fonte: Acervo pessoal de Lila Bemerguy

Figura 13 - Trapiche muncipal, em 1961

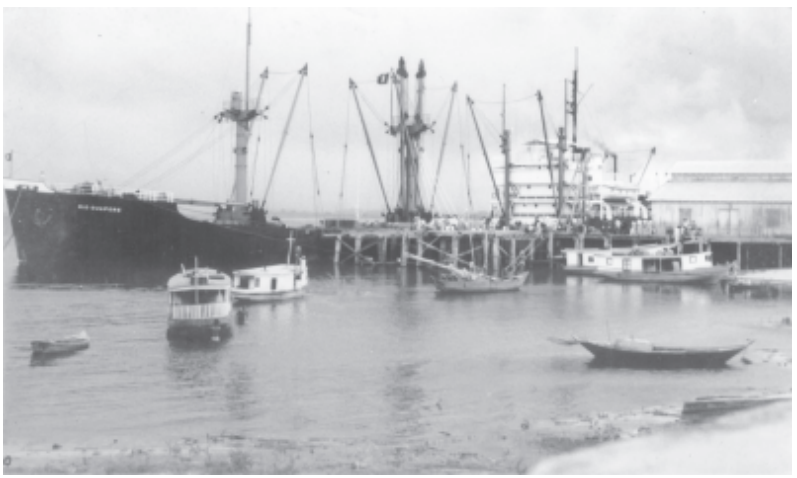

Fotografia: Vidal Bemerguy

Fonte: Acervo pessoal de Emir Bemerguy 
A orla de Santarém, banhada pelo rio Tapajós, é outro local que passou por modificações por conta do crescimento e urbanização da cidade. Conforme descreve Emir Bemerguy (2010, p.248): "Nossa orla fluvial era um balneário só, de ponta a ponta, que sumiu sob aterramentos de onde nasceram a Praça do Pescador e a Avenida Tapajós, de beleza satisfatória, consolando-nos um pouco das agressões à paisagem."

Percebemos nas imagens de 1953 (Figura 15) e 1961 (Figura 17) a visão geral da orla descrita pelo autor. A necessidade de construir ruas e praças modificou a paisagem, embora reconheça o autor que a mesma ainda permanece "satisfatoriamente" bela. Ainda assim, o poeta reclama em rima composta em 1983: “Aquele areal bonito, branquinho, limpo e infinito, do teu litoral faz pena: virou esgoto e avenida, uma extensão poluída, uma raiva santarena!" (BEMERGUY, 2007, p.26). A visão geral da orla em 2010 pode ser vista nas imagens das figuras 14 e 16.

Figura 14 - Frente da cidade, com visão da igreja

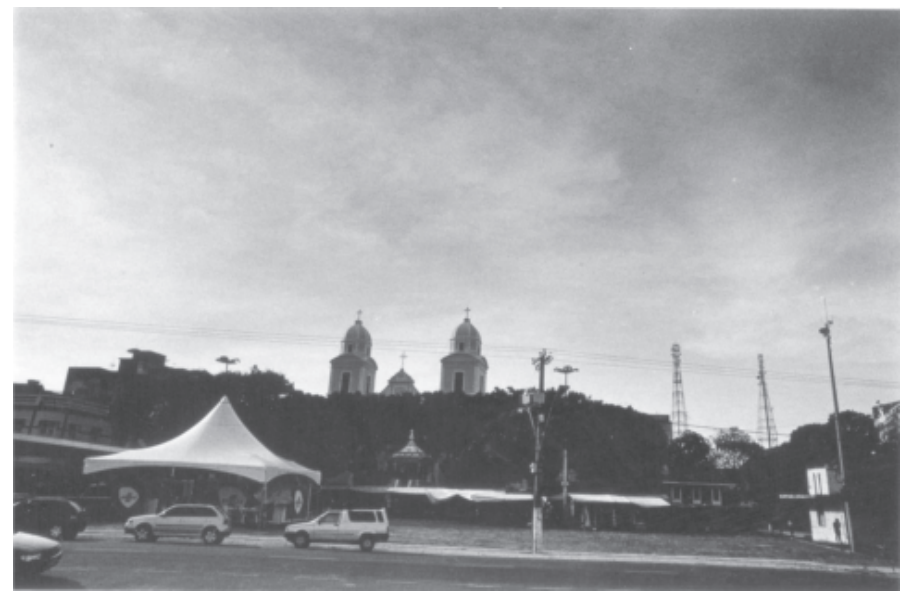

Fotografia: Lila Bemerguy

Fonte: Acervo pessoal de Lila Bemerguy 
Figura 15 - Frente da cidade, com a praça da matriz, em 1961

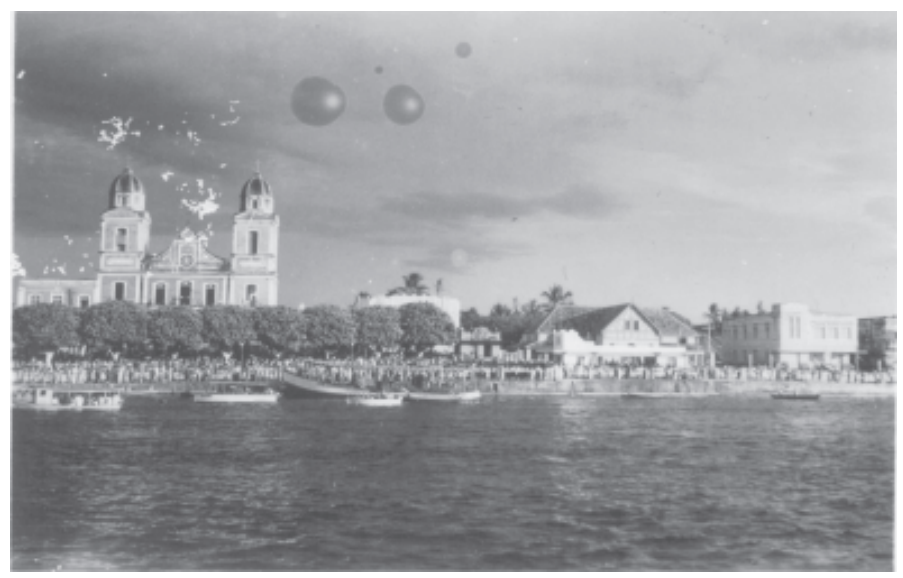

Fotografia: Vidal Bemerguy

Fonte: Acervo pessoal de Emir Bemerguy

Figura 16 - Orla da cidade, em 2010

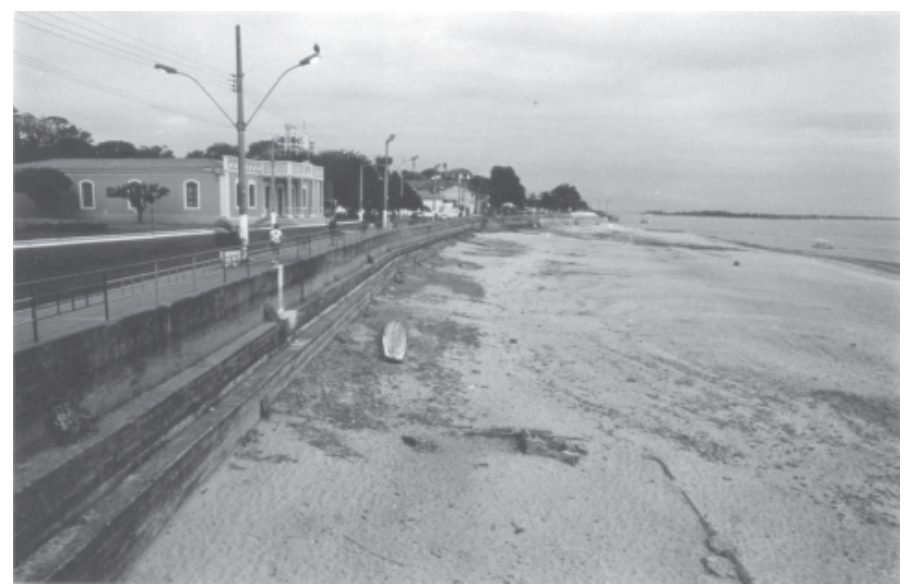

Fotografia: Lila Bemerguy

Fonte: Acervo pessoal de Lila Bemerguy 
Figura 17 - Orla da cidade, em 1953

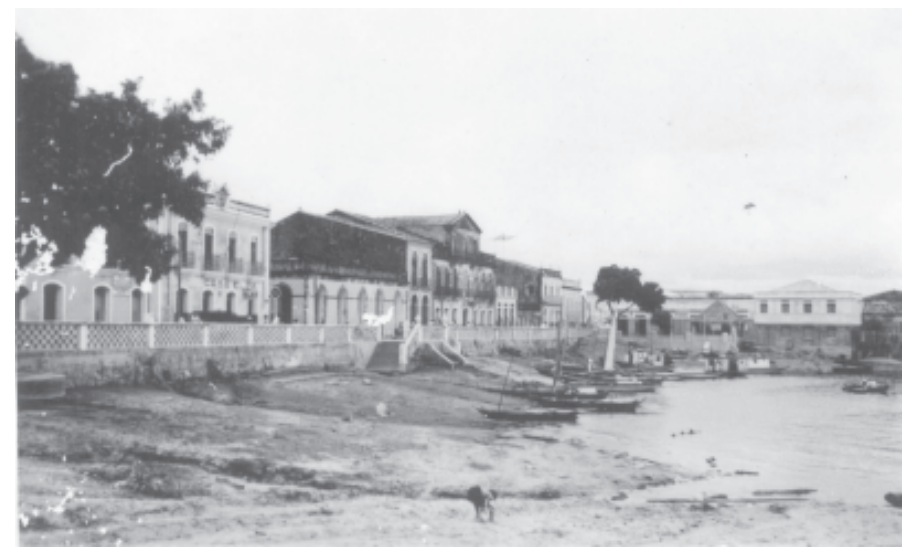

Fotografia: Vidal Bemerguy

Fonte: Acervo pessoal de Emir Bemerguy

No decorrer da produção de imagens para o projeto, tive a oportunidade de re-conhecer uma cidade diferente daquela que fazia parte das lembranças de infância, guardadas intactas nos anos que estive longe, visitando a cidade somente para rever a família, sem perceber de perto as modificações sofridas na cena urbana. E ao conhecer e confrontar com paisagens e lugares dos anos de 1950 a 1970, período das imagens coletadas, o sentimento de transformação é acentuado, pois alguns desses locais sequer existem mais, pois deram lugar a outras edificações. A Santarém do passado permanece somente nas fotografias. A cidade cresce, urbaniza-se e prédios históricos definham, como se a conservação fosse incompatível com o progresso. O poeta tinha razão. 


\section{Considerações finais}

Ao tecer comentários acerca dos lugares fotografados no projeto, relacionando-os com trechos da poesia de Emir Bemerguy, refletimos que as edificações e ruas de determinada cidade expõem o modo como o homem se coloca nesses espaços. Malard (apud ALMEIDA, 1995, n.p.) defende a ideia do homem como um "ser-no-mundo" e, portanto, sua existência está ligada ao espaço. $\mathrm{O}$ fato de habitar determinada cidade, seja por nela haver nascido ou por escolha, estabelece as ligações do homem com seu lugar, no qual planejará a vida e deverá construir seus laços, suas raízes.

Neste sentido, Almeida (1995, n.p.) afirma que "como todas as ações humanas têm lugar no espaço, este espaço é o espaço arquitetural que é dotado de todos os significados que a existência humana possui". Significados comuns aos moradores e que podem ser reconhecidos nos prédios e na importância dada a cada local, que irá ditar a sua preservação ou destruição, principalmente por serem construções expostas e vulneráveis.

Dentre os lugares visitados para a pesquisa, estivemos em duas casas residenciais construídas no século XIX, preservadas principalmente pelo fato de ali ainda habitarem os moradores da família proprietária, ambos idosos, com idades entre 80 e 90 anos. Móveis, quadros e objetos antigos emprestaram a essas duas casas uma atmosfera quase sagrada, sentida pelo apego dos donos aos locais e percebida no esforço em preservar sua própria história.

A cidade, como aglomerado urbano habitado pelo ser humano, o reflete, "edificada onde e como ele deseja, refletindo a cultura, as crenças, as formas de uso e os hábitos dos habitantes do lugar. Pensar a cidade é também pensar a construção humana, uma intervenção ou arte temporal e espacial delimitada". (MUSSELIN; BELLINI, 2007, p.223).

Como moradora de Santarém, voltando à cidade depois de 18 anos em Belém, pude vivenciá-la a partir de um olhar que não o meu, e 
revisitar lugares importantes para aquele que os registrou, já que o ato de fotografar é um ato de atribuir importância. Num segundo momento, esses lugares já modificados passaram pelo meu próprio olhar, contaminados por cenas de um passado que não vivi, mas que foi vivido por Vidal Bemerguy e por tantos outros que já se foram, inclusive por meu pai, que aos 78 anos emociona-se ao ver as fotografias de "seu tempo".

Certo dia, ao mostrar um dos álbuns que serviram como fonte desta pesquisa, ele tinha lágrimas nos olhos ao dizer: "parece que estou vendo! O rio, o bar Mascote, o trapiche...". A atitude saudosa do poeta Emir Bemerguy demonstra o quanto os espaços, os lugares fazem parte da vida de cada pessoa, afetam e por elas são afetados. Lugares de vivência, onde o homem reconhece a si e a sua história.

\section{Referências}

\section{ALMEIDA, Maristela. Análise das interações entre o homem e o} ambiente. 1995. Dissertação (Mestrado em Engenharia de Produção) - Universidade Federal de Santa Catarina, Florianópolis. Disponível em: <http://www.eps.ufsc.br/disserta/maristela/cap2/ CP2_MOR.htm\#21 >.Acesso em: 15 nov. 2008. n.p.

BEMERGUY, Emir. Momentos poéticos. Santarém: Instituto Cultural Boanerges Sena, 2007.

. Santarenices: coisas de Santarém. Santarém: Instituto Cultural Boanerges Sena, 2010.

. Entrevista concedida a Lila Bemerguy, em 22 de maio de 2010, na residência do entrevistado em Santarém. 
CALVINO, Ítalo. Amores difíceis. São Paulo: Companhia das Letras, 1992.

CUNHA, Ademar. Entrevista concedida a Lila Bemerguy, em 16 de maio de 2010, na residência do entrevistado em Belterra.

FERNANDES JUNIOR, Rubens. Fotografia paraense: militância e dissonância poética. In: BELÉM. Secretaria de Estado de Cultura. Fotografia contemporânea paraense: Panorama 80/90. Belém, 2002. p.16-41.

FONSECA, Wilson. Meu baú mocorongo. Santarém: Secretaria de Estado de Cultura, 2006. v. 1.

GRANGEIRO, Cândido Domingues. As artes de um negócio: a febre photographica. São Paulo: Mercado de Letras, 2000.

KOSSOY, Boris. Os tempos da fotografia: o efêmero e o perpétuo. São Paulo: Ateliê Editorial, 2007.

- Dicionário histórico fotográfico brasileiro. Rio de Janeiro: Instituto Moreira Salles, 2002.

MUCELIN, Carlos Alberto; BELLINI, Luzia Marta. A percepção ambiental urbana com uso de imagens fotográficas: um instrumento semiótico denominado jogo da percepção. Discursos Fotográficos, Londrina, v.3, n.3, p.221-248, 2007.

NUNES, Benedito. Amazônia reinventada. IN: II FOTONORTE AMAZÔNIA: o olhar sem fronteiras. Rio de Janeiro: Funarte, 1998. 
SIMONIAN, Lígia T. L.. Uma relação que se amplia: fotografia e ciência sobre e na Amazônia. In: KAWHAGE, C.; RUGGERI, S. (Org). Imagens e pesquisa: ferramentas de compreensão da realidade amazônica. Belém: Editora do NAEA, 2007.p. 15-52.

SONTAG, Susan. Sobre a fotografia. São Paulo: Companhia das Letras, 2004. 